\title{
Cork extractives exhibit thermo-oxidative protection properties in polypropylene-cork composites and as direct additives for polypropylene
}

\author{
Ivo M. Aroso a, b, *, Emanuel M. Fernandes ${ }^{\text {a, b }}$, Ricardo A. Pires ${ }^{\text {a, b }}$, João F. Mano a, b, \\ Rui L. Reis ${ }^{\mathrm{a}} \mathrm{b}$ \\ a 3Bs Research Group - Biomaterials, Biodegradables and Biomimetics, University of Minho, Headquarters of the European Institute of Excellence on Tissue \\ Engineering and Regenerative Medicine, AvePark, 4806-909 Taipas, Guimarães, Portugal \\ b ICVS/3B's - PT Government Associate Laboratory, Braga, Guimarães, Portugal
}

\section{A R T I C L E I N F O}

\section{Article history:}

Received 30 October 2014

Received in revised form

18 February 2015

Accepted 11 March 2015

Available online 21 March 2015

\section{Keywords:}

Polypropylene

Cork

Composites

Thermo-oxidation

Oxidation induction time

Oxidation onset temperature

\begin{abstract}
A B S T R A C T
The thermo-oxidative stability of polypropylene (PP) in composites containing 15 wt.\% of cork and the performance of selected cork extracts as stabilizing additives for PP was evaluated by Oxidation Induction Time (OIT) and by Oxidation Onset Temperature (OOT). The results showed that cork increases the OIT of PP in the composite and it was identified that the cork extractives fraction is responsible for such behavior. Selected cork extracts with high antioxidant capacity (determined by dpph radical scavenging and oxygen reactive absorbance capacity assays) were compounded by extrusion with PP in 0.5 and $1.5 \mathrm{wt} . \%$. It was found that the ethanol extract is the most effective as thermo-oxidative stabilizer for PP. At the loading level of $1.5 \%$, the OIT increases from 3.8 (neat PP) to $29.7 \mathrm{~min}$ at $200^{\circ} \mathrm{C}$ and from 1.2 (neat PP) to $9.0 \mathrm{~min}$ at $220^{\circ} \mathrm{C}$. The OOT also increases from $216^{\circ} \mathrm{C}$ (neat PP) to $247{ }^{\circ} \mathrm{C}$. Mechanical tests, performed on PP loaded with the cork extracts, showed that the presence of these extracts has no significant effect on the polymer mechanical performance. The results demonstrate the suitability of cork as a source of thermo-oxidative stabilizing additives for the formulation of polyolefins, and enable the exploitation of new routes of cork valorization.
\end{abstract}

๑) 2015 Published by Elsevier Ltd.

\section{Introduction}

Cork is the outer bark of the oak tree Quercus suber L., which mainly grows in western Mediterranean regions. The bark is manually harvested every 9-12 years in a process that does not damage the tree, allowing it to continue to develop normally. Europe holds $\mathrm{ca} 60 \%$ of the total area of cork oak forests and harvests more than $80 \%$ of the World's cork. Portugal is the major producer, being responsible for the processing of $49 \%$ of the total amount of cork harvested in the World [1,2].

The cork chemical composition is variable and is dependent on different factors, such as, geographical origin, climate, age of the trees, etc. Anyway, typical compositions are within the ranges:

\footnotetext{
* Corresponding author. 3B's Research Group - Biomaterials, Biodegradables and Biomimetics, University of Minho, AvePark, Zona Industrial da Gandra, 4806-909 Caldas das Taipas, Portugal. Tel.: +351 253 510900; fax: +351 253510909.

E-mail address: ivo.aroso@dep.uminho.pt (I.M. Aroso).
}

$25-40 \%$ for suberin; followed by $13-29 \%$ for lignin; $6-25 \%$ for polysaccharides; and $8-24 \%$ for extractives [3-5]. Structurally, cork is constituted by an arrangement of cells (that have lost its internal content) with highly suberized walls. When observed on the microscope, this structure resembles a honeycomb pattern. This material presents some remarkable properties, such as: near-zero Poisson coefficient; complete recovery of shape after compression; among many others [6-8]. These properties are devised from its unique chemical composition and morphological structure.

The main industrial application of cork is for the production of stoppers. However, there are large quantities of cork (in different forms), whose lower quality or format limitation, does not allow its processing for the preparation of stoppers. This large amount of unused cork (usually considered as a by-product) has prompted the development of other applications for this unique natural material. In this scope, a series of applications for cork and cork-based materials have been developed; these include the production of: lightweight, sound and vibration insulation materials for housing and aerospace applications; cork-rubber composites for 
automobile engine gaskets; or decorative items. Despite these alternative uses, up to $25 \%$ of the processed cork is still transformed into powder that has no direct application [2]. Therefore, the present solution is to use it as fuel for energy recovery. The existence of such an unexploited stream of this natural raw material has prompted the development of new routes for its valorization.

The use of waste materials as fillers for the composite production is receiving increasing attention as an approach to increase the economical value of such streams. In particular, if the fillers are of natural origin and renewable resources, it can result in a material with higher green awareness and environmental benefits. Additionally, some natural fillers can impart new and or improved properties to the composite.

There is an increasing interest (from both the industry and the scientific community) in the development of cork-polymer composites [9-11]. The use of cork has a number of advantages when compared to other lignocellulosic materials. It can be regarded as imminently hydrophobic thus reducing the incompatibility with most polymers (that usually present a very low polarity); while its low density and its high capacity as thermal and acoustic insulator are qualities that are highly desired in diverse fields of application. Recent studies on the development of cork-polymer composites have focused on the increase of the interfacial adhesion by using different chemical (e.g. maleic anhydride [10-12]) and bio-based coupling agents $[13,14]$. It has been also reported: the improvement of the mechanical properties through the use of natural fibers as reinforcement [15-17]; the surface modifications of the natural component [17-19]; the increment of the damping properties $[20,21]$; the enhancement of the acoustic insulation [11,21]; and, more recently, the combination of cork with biodegradable and natural origin polymers $[22,23]$. As a result, solutions where cork is combined with high consumption polymers, such as, typical thermoplastic and thermosets used in the construction, transportation and aeronautical fields, have been developed.

Most polymeric materials are susceptible to degradation initiated by external factors, such as, light, heat, oxygen, humidity or shear forces [24-26]. The chemical modifications generated during this process result on the reduction of the mechanical performance and, therefore, decrease of the service life [27]. In the case of polypropylene (PP), its degradation involves the formation of primary alkyl radicals triggered by factors, such as, high temperatures, oxidative atmosphere and mechanical forces and amplified if in the presence of impurities and transition metals. The alkyl radicals can be converted to peroxy radicals in the presence of oxygen, which could further react to yield hydroperoxides [28-30]. Therefore, the rate of degradation of PP is influenced by the presence of radicals and reactive oxygen species. These thermo-oxidative processes from the degradation of PP can occur already during processing and, thus, strategies to reduce its effects usually involve the addition of stabilizing agents during the processing stages.

In order to minimize degradation, it is common to add different types of stabilizers that can act in the different stages of the polymer's lifetime. The most common type of stabilizers used during the processing stages are phosphorous-based, while hindered phenols can also be used to improve the lifetime of the material. Although these are commonly of synthetic origin, the possibility of using natural antioxidants [31-33] and modified natural phenolic extracts [34] as stabilizing additives has been proposed. In a recent study, it was shown that the thermo-oxidative properties of PP in composite materials containing cork are considerably improved, because of the cork material [12]. Further research work is required to identify which are the cork constituents responsible for this effect and evaluate their potential as bio-based stabilizing agents. In the present work we studied the thermo-oxidative properties of PP in composites containing $15 \mathrm{wt}$.\% of cork in order to identify which cork constituents are responsible for the above-mentioned thermooxidative protection. Moreover, we have evaluated if these can be further valorized as direct stabilizing agents for PP and we have quantified the protective effect by oxidation induction time (OIT) and oxidation onset temperature (OOT) parameters.

\section{Materials and methods}

\subsection{Materials and reagents}

Cork powder was selected and collected at the industrial facilities directly from the processing machines and used as received (Amorim Cork Composites, Portugal). This material is produced by reprocessing of cork scrapes from different origins. The leftovers are collected, further milled and sorted by density and particle size in a high frequency industrial vibrating equipment, to obtain homogenous fractions, before further industrial use. From the different fractions arising from this process, for this work, the criterion for selecting the cork powder sample was the availability in large quantities and the purity (absence of other contaminants). The selected cork powder was collected at the industrial facility during the normal production process, and was considered to be representative of the daily operations by the industry responsible. The matrix was a PP homopolymer (1374 E2, ExxonMobil, Ger-

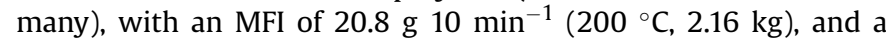
melting point of $162{ }^{\circ} \mathrm{C}$, that was transformed into powder and supplied by Pallmann Maschinenfabrik GmbH \& Co. (Germany). All chemical reagents were analytical grade. Ethanol and chloroform were purchased from Fisher Chemicals, while dichloromethane, methanol sulfuric acid, Pentaerythritol tetrakis(3-(3,5-di-tertbutyl-4-hydroxyphenyl)propionate), Folin-Ciocalteu reagent, gallic acid, 2,2-diphenyl-1-picrylhydrazyl, 2,2-azobis(2methylpropionamide)dihydrochloride, fluorescein sodium salt and 6-hydroxy-2,5,7,8-tetramethylchromane-2-carboxylic acid (Trolox) were purchased from Sigma-Aldrich. Sodium hydroxide and sodium carbonate were acquired from Fluka.

\subsection{Cork powder characterization and preparation of extractive- free cork powder}

The cork powder particle size distribution was determined on an analytical sieve shaker (model AS200, Retsch, Germany) equipped with a cascade of different mesh sieves. The chemical composition was determined in terms of extractives, suberin and lignin, following already established protocols reported elsewhere $[3,35]$. The extractive fraction was quantified as the combined mass of the material solubilized and recovered after successive Soxhlet extractions with dichloromethane, ethanol and water, for periods of $6 \mathrm{~h}$ each. The resulting cork powder was defined as extractivesfree cork powder and was further used for the preparation of composites (hereafter designated by PP-Cork-EF) and for the suberin content determination. The suberin content was quantified as the chloroform soluble fraction after submitting the extractive-free cork powder to alkaline methanolysis. In short, the cork material was kept under reflux in methanol containing $0.1 \mathrm{M}$ sodium hydroxide $(1 \mathrm{~g}$ per $50 \mathrm{~mL}$ ), for $6 \mathrm{~h}$, after which, the liquid fraction was recovered, acidified to $\mathrm{pH} 6$ with hydrochloric acid; after solvent removal, the solid residue was suspended in water and extracted with chloroform. The suberin material was obtained by removal of the chloroform under vacuum in a rotatory evaporator. The lignin fraction was obtained from the dessuberized cork material by processing it with $72 \%$ sulfuric acid in a $15 \mathrm{~mL}$ per $1 \mathrm{~g}$ of cork ratio, at room temperature, under constant stirring. After $2 \mathrm{~h}, 30 \mathrm{~mL}$ of concentrated sulfuric acid per gram of material was added and the mixture refluxed for $4 \mathrm{~h}$. After thorough washing with distilled 
water, the lignin material was recovered as the enduring solid residue.

\subsection{Cork extracts and antioxidant properties}

Cork extracts were obtained by direct hot solvent extraction from cork powder. The extracts were obtained by maintaining cork powder in contact with the selected solvents $(1 \mathrm{~g}$ per $50 \mathrm{~mL})$, under reflux conditions, for a period of $6 \mathrm{~h}$. After cooling, the liquid fraction was recovered by filtration and concentrated by vacuum evaporation. After freeze-drying, the extracts were recovered in the form of powders, stored in a desiccator and protected from light until further use. The extracts were obtained with water, ethanol and water:ethanol 1:1 (v/v) and are hereafter designated E_H2O, E_EtOH and E_EtOH50, respectively.

The cork extracts were characterized for its total phenolic content (TPC) and its antioxidant potential as scavengers of radicals and reactive oxygen species. The TPC was determined by the Folin-Ciocalteu assay; the radical scavenging capacity by the 2,2diphenyl-1-picrylhydrazyl radical scavenging assay (dpph assay) and the reactive oxygen species scavenging by the oxygen radical absorbance capacity (ORAC) assay.

The TPC was determined according to the Folin-Ciocalteu method [36] and adapted from Santos et al. [37]. Briefly, $40 \mu \mathrm{L}$ of a suitable sample dilution were added to $500 \mu \mathrm{L}$ of diluted Folin reagent (1:10 with water) and $460 \mu \mathrm{L}$ of a $75 \mathrm{~g} / \mathrm{L}$ aqueous sodium carbonate solution. The reaction mixtures were kept at $50{ }^{\circ} \mathrm{C}$ for $5 \mathrm{~min}$ and, after cooling, $250 \mu \mathrm{L}$ were transferred to individual wells of a 96 well microplate and the absorbance was read at $760 \mathrm{~nm}$ (microplate reader Synergy HT, Bio Tek, USA). The TPC was calculated from a standard curve with gallic acid (range 1.5-20 $\mu \mathrm{g} / \mathrm{L}$ ) and expressed as mg of gallic acid equivalents per gram of extract, $\mathrm{mgGA}_{\text {eq }} / \mathrm{g}_{\text {extract. }}$

The dpph radical scavenging activity was determined following a methodology adapted from by Santos et al. [37]. Briefly, $35 \mu \mathrm{L}$ of suitable dilutions of extract solutions were added to $900 \mu \mathrm{L}$ of a solution of dpph in methanol with initial absorbance of $0.850 \pm 0.01$. After vigorous vortexing the reaction solutions were kept in the dark for $30 \mathrm{~min}$. The absorbance of $200 \mu \mathrm{L}$ aliquots was read at $517 \mathrm{~nm}$ (microplate reader, Synergy HT, Bio Tek, USA). The $\mathrm{EC}_{50}$ was calculated from the plot of scavenging activity against extract concentration and represent the amount of extract necessary to decrease the initial dpph concentration by $50 \%$.

The ORAC antioxidant test procedure was adapted from the methodology described by Huang et al. [38]. The reaction mixture was obtained by mixing: $25 \mu \mathrm{L}$ of sample solution with $25 \mu \mathrm{L}$ of $250 \mathrm{mM}$ AAPH (2,2'-Azobis(2-methylpropionamidine)dihydrochloride) solution in PBS and $150 \mu \mathrm{L}$ of a $0.025 \mu \mathrm{M}$ fluorescein solution. Fluorescein measurements were performed in a microplate reader (Synergy HT, Bio Tek, USA) equipped with adequate fluorescence filters. The white opaque 96 well plaque was maintained at $37{ }^{\circ} \mathrm{C}$, with readings taken at 2 min interval with agitation in between. Fluorescence conditions were excitation at $485 \mathrm{~nm}$ and emission at $520 \mathrm{~nm}$. The ORAC value was calculated as the mass of Trolox equivalents per mass of extract, TE.

\subsection{Twin-screw extrusion compounding}

Prior to compounding, all natural raw materials were dried under vacuum at $30^{\circ} \mathrm{C}$ during $24 \mathrm{~h}$ to stabilize the cork moisture content. The compositions: neat PP; PP-cork powder composites and PP-Cork extracts, were compounded in a Rondol SCF modular co-rotating twin-screw extruder with the screws diameter of $16 \mathrm{~mm}$, a length to diameter ratio $(L / D)=25$ and a single strand die of $3 \mathrm{~mm}$. All processed compositions are discriminated in Table 1 , including the temperature profile along the barrel to the die and the rotation screws. The PP-Cork extracts were compounded in a two-step procedure. The extracts were initially solubilized/suspended in ethanol and added to the PP powder in order to obtain the desired loading levels. After thorough mixing, the mixture was dried under vacuum at $30^{\circ} \mathrm{C}$ for $24 \mathrm{~h}$ to guarantee complete solvent removal. The resulting mixture was then extruded according the conditions indicated in Table 1. The extruded was cooled in a water bath, pelletized in an SF SCHEER \& CIE (Germany) equipment and dried at $30^{\circ} \mathrm{C}$ under vacuum during $24 \mathrm{~h}$. The final materials were stored in polyethylene bags until further use.

\subsection{Thermal properties}

The thermal-oxidative properties were accessed by means of OIT and OOT tests determined using a differential scanning calorimeter (DSC, T. A. Instruments, model DSCQ100, USA), with sample mass of 7-9 mg in open aluminum pans. For the OIT determination, samples were heated to the test temperature (200 and $220{ }^{\circ} \mathrm{C}$ ) under nitrogen atmosphere and stabilized for $2 \mathrm{~min}$. Purge gas was commuted to oxygen and the heat flow $v s$ time was recorded. The test was considered completed on the observation of the exothermal peak caused by the samples oxidation. The OIT value was determined from the time elapsed between the switch to oxygen purge gas and the onset point between baseline and oxidation curve. The OOT determination was performed by equilibrating the temperature to $20^{\circ} \mathrm{C}$ before changing the purge gas to oxygen, followed by temperature increase at the rate of $10{ }^{\circ} \mathrm{C} \mathrm{min}-1$, recording the heat flow $v$ s temperature. The assay was considered complete upon the observation of the exothermic oxidation peak. The OOT value was determined from the temperature of the onset of the oxidation process. DSC analysis of cork extracts was performed using aluminum pans with lids and $7-10 \mathrm{mg}$ of sample mass, from $20^{\circ} \mathrm{C}$ to $200^{\circ} \mathrm{C}$ at $10^{\circ} \mathrm{C} / \mathrm{min}$, under oxygen atmosphere.

\subsection{Mechanical properties}

The PP-cork extracts pellets were processed in boards by compression molding, using the conditions from a previous study [12]. Tensile specimens with a dog bone shape, gauge length of $20 \mathrm{~mm}$ and cross section $(4 \times 2 \mathrm{~mm})$ were cut from molded boards using a computer numerical control CNC machine (Roland 3D Plotter MDX-20, UK). The tensile properties of the PP-Cork extracts were measured using an Instron 4505 Universal Machine (USA). The tests were conducted using a $1 \mathrm{kN}$ load cell and a crosshead speed of $5 \mathrm{~mm} \mathrm{~min}{ }^{-1}$ until rupture. The average and standard deviations were determined using 5 specimens per condition.

\section{Results and discussion}

\subsection{Cork powder characterization}

The cork powder sample was characterized in terms of the particle size distribution and for its chemical composition. The particle size distribution analysis and the chemical composition results are presented in Table 2.

The results show that the cork powder is constituted by a narrow range of particle sizes, concentrated within two of the ranges analyzed, being the higher amount ( $84 \%$ ) between 0.25 and $0.5 \mathrm{~mm}$ and a smaller percentage (15\%) between 0.125 and $0.25 \mathrm{~mm}$. This particle size distribution reflects the screening process employed in the industrial facility.

The determination of the cork's chemical composition revealed that it is constituted by approximately $12 \%$ extractives, $33 \%$ suberin and $25 \%$ lignin, with the remaining being mainly polysaccharides 
Table 1

Compositions and processing conditions used on the preparation of the PP-cork composites and PP-cork extracts.

\begin{tabular}{|c|c|c|c|c|c|}
\hline \multirow[t]{2}{*}{ Sample } & \multicolumn{3}{|c|}{ Components } & \multicolumn{2}{|l|}{ Processing conditions } \\
\hline & PP (wt.\%) & Cork (wt.\%) & Cork extract (wt.\%) & Temperature profile $\left({ }^{\circ} \mathrm{C}\right)$ & Screw speed (rpm) \\
\hline $\mathrm{PP}$ & 100 & & & $100 ; 170 ; 180 ; 180 ; 185$ & 80 \\
\hline PP-cork & 85 & 15 & & & \\
\hline $\mathrm{PP}-$ cork-EF & 85 & 15 & & & \\
\hline E_H2O-0.5\% & 99.5 & & 0.5 & & \\
\hline E_H2O-1.5\% & 98.5 & & 1.5 & & \\
\hline E_EtOH-0.5\% & 99.5 & & 0.5 & & \\
\hline E_EtOH-1.5\% & 98.5 & & 1.5 & & \\
\hline E_EtOH50-0.5\% & 99.5 & & 0.5 & & \\
\hline E_EtOH50-1.5\% & 98.5 & & 1.5 & & \\
\hline IR-0.5\% & \multicolumn{5}{|c|}{ PP with 0.5\% Pentaerythritol tetrakis(3-(3,5-di-tert-butyl-4-hydroxyphenyl)propionate) } \\
\hline
\end{tabular}

and inorganic fractions. The determined values are in accordance with the ones reported by other authors and summarized by Silva et al. [4]; they are also within the range of the intrinsic variability that is present for this natural material.

\section{2. $P P-$ cork composites}

In accordance with Table 1, two PP-cork composite formulations were prepared (one with untreated cork powder and another one with extractives-free cork powder). The thermo-oxidative properties of these formulations were assessed by the OIT at the temperature of $200{ }^{\circ} \mathrm{C}$. The DSC curves and the values determined for the OIT are shown in Fig. 1.

From the DSC OIT curves, it is apparent that the neat PP, in the absence of stabilizers, is prone to rapid oxidation when submitted to high temperature and an oxidative atmosphere. Upon the switch of the purge gas to molecular oxygen, the heat flow curve directs to negative values (resulting from the exothermal oxidation process) at increasing rate with the establishing of an accentuated exothermal peak in very short time.

The OIT curve for the PP-cork composite formulations, after the switch of the purge gas to oxygen, shows a flat area that extends up to almost 40 min within the total time of the assay, resulting in an OIT value of $30.3 \pm 0.3 \mathrm{~min}$. The almost zero value for the variation of the heat flow in the referred region is a result of the absence of thermal processes. When comparing the DSC curves and OIT values for the PP-cork composite and the neat PP we can conclude that

Table 2

Cork powder particle size distribution and chemical composition.

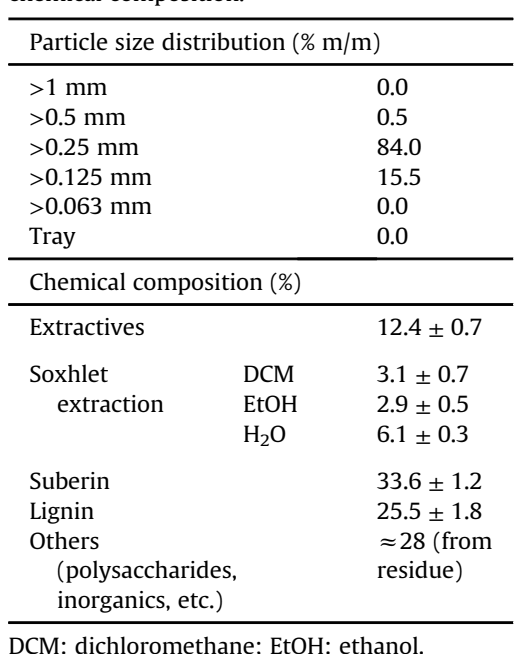

the presence of the cork material is imparting an extra stabilization to the composite and, consequently, also to the PP. This result is in agreement with a recent study by Fernandes et al. [12] where it was shown that the cork used in the PP-Cork composites induces an increase of the OIT. Reducing the cork particle size, and consequently increasing the surface area of the cork particles, a higher thermal-oxidative protection of the PP matrix was achieved [12]. It is then reasonable to assume that within the cork material composition there are molecules and/or molecular structures that are able to function as thermo-oxidative stabilizers.

The proposed mechanism for PP oxidation involves an initiation step of formation of primary alkyl radicals through the homolytic cleavage of a carbon-hydrogen bond. This leads to PP degradation which can be further enhanced by the presence of oxygen [30]. Hence, for PP, a stabilizing system will have to act at two levels, scavenging of radicals and quenching of reactive oxygen species. In cork, the extractive's fraction is composed by low molecular weight molecules, e.g. polyphenols, which are known to present the capacity to scavenge radicals [37,39]. In this context, we hypothesize that these molecules are the responsible for the stabilizing effect observed for $\mathrm{PP}-$ cork composites.

The preparation of extractives-free cork powder was achieved through the selective removal of this fraction by a procedure employing 3 sequential Soxhlet extractions with dichloromethane, ethanol and water. The extractive-free cork powder was used to obtain a PP-cork-EF composite, using the processing conditions previously described. The OIT curve obtained for such composite is also shown in Fig. 1. When the extractives fraction is removed, the

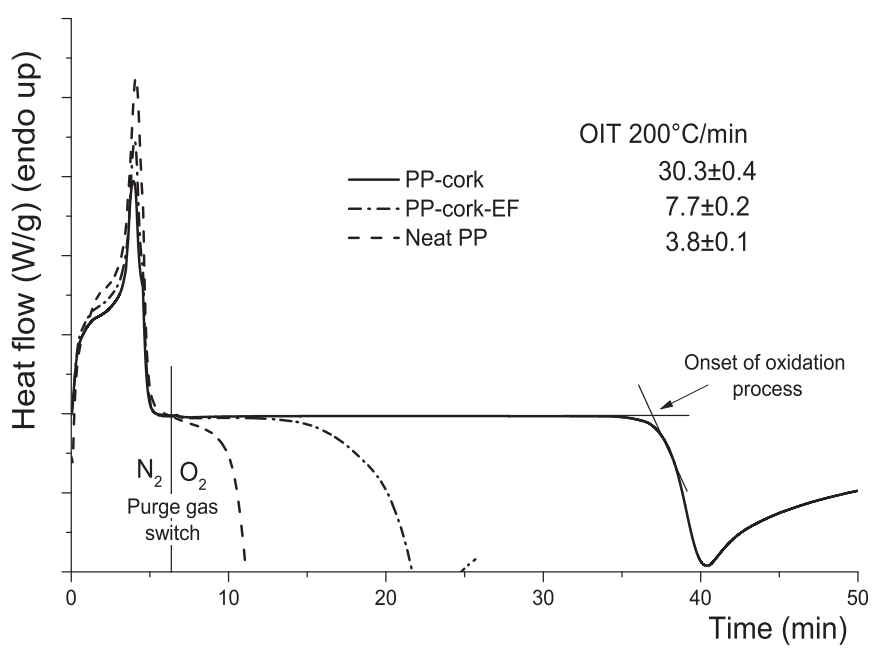

Fig. 1. Determination of the OIT $\left(200^{\circ} \mathrm{C}\right)$ for the PP-Cork composites and the neat PP. 
stabilizing effect provided by the cork powder is significantly reduced, reaching an OIT value of only $7.7 \pm 0.2 \mathrm{~min}$ (which compares to $30.3 \pm 0.4 \mathrm{~min}$ for the untreated PP-cork). The reminiscent protective effect can be the result of incomplete removal of the extractive fraction and/or antioxidant activity provided by other cork constituents. In fact, Conde et al. [40] have shown that ligninderived fractions can have some protective effect. Nevertheless, our data clearly indicate that the protective effect arises primarily from the extractive fraction.

\subsection{Cork extracts and antioxidant properties}

The cork extractive's fraction is composed of low molecular weight molecules that aren't covalently bonded to the structural elements of the cell wall (suberin and lignin). Therefore, they are easily extracted using suitable solvents. Partitions of the cork extractives were obtained through direct extractions using water, ethanol and its mixture in a 1:1 ratio.

Such extracts were found to possess high phenolic content and are, therefore, premium candidates for the observed thermooxidative stabilization of the polymer in the cork-PP composites. The results for the characterization of the TPC, and the radicals (dpph assay) and reactive oxygen species (ORAC assay) scavenging properties of such extracts are summarized in Table 3, alongside with the yields of extraction.

The results show that the TPC is higher for E_EtOH50 and lower for E_EtOH. When comparing the TPC results with the values from the dpph assay, recalling that these are expressed as an efficient concentration (and, thus, the lower this concentration is, the more effective it is the extract), it can be observed that the radical scavenging capacity is proportional to the TPC of the extract. Indeed, E_EtOH50 is the most effective $(5.32 \mu \mathrm{g} / \mathrm{mL})$ extract for radicals scavenging and E_EtOH $(9.44 \mu \mathrm{g} / \mathrm{mL})$ is the least effective. The ORAC assay measures the extract effectiveness in the absorption of oxygen radical species and, as for the dpph evaluation, the results show that E_EtOH50 (2.11 TE) is the extract with highest activity followed by E_EtOH (1.88 TE). The results for the ORAC assay are consistent with the higher anti-oxidant performance of E_EtOH50, although, in this assay the E_EtOH had a better performance than the E_H2O. This latter variation confirms that the performance of the different extracts is dependent on the nature of the constituent molecules. The water and ethanol cork extracts are composed of numerous molecules with complex structures and is not completely known. However, different phenolic acids, ellagitannins and flavonoids have been identified [37,39].

\subsection{Polypropylene-cork extracts}

The cork extracts E_H2O, E_EtOH and E_EtOH50 were processed as additives for the stabilization of PP at two loading levels, i.e. 0.5 and 1.5 wt.\%. The mixtures were prepared by solubilizing/suspending the selected extracts in ethanol to facilitate its dispersion within the PP powder. The mixtures were processed by extrusion in order to obtain homogenous distribution of the components. The processing conditions employed were the same as described for the processing of $\mathrm{PP}$-cork composites.

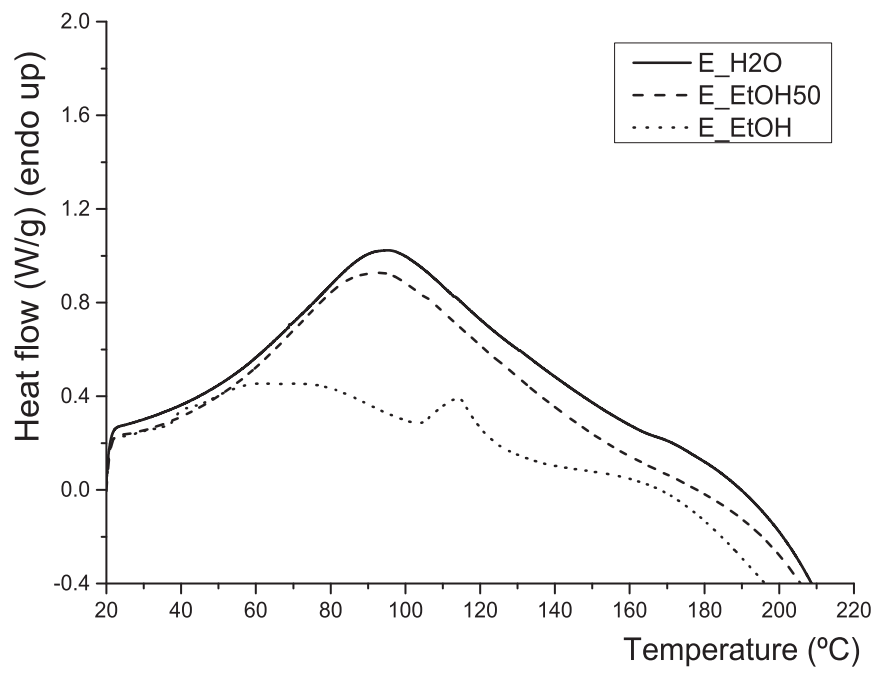

Fig. 2. DSC analysis of cork extracts under oxygen atmosphere $\left(10^{\circ} \mathrm{C} / \mathrm{min}\right)$.

The thermal properties of the cork extracts, before processing, were assessed by DSC analysis under oxygen atmosphere. The results are presented in Fig. 2. For lower temperatures, the thermograms present an endothermic band, from approximately $30^{\circ} \mathrm{C}$ to $120{ }^{\circ} \mathrm{C}$. The most relevant feature is the onset of an oxidation process (exothermal process) observed for higher temperatures, namely above the $180{ }^{\circ} \mathrm{C}$. During processing, temperatures of $180^{\circ} \mathrm{C}$ (and $185^{\circ} \mathrm{C}$ for the dye) are used, but the extracts residence time at this temperature will be short and the $\mathrm{O}_{2}$ present will be limited. Therefore, it is not expected the occurrence of significant degradation of the extract during the processing stage.

After being transformed into pellets (of approx. $5 \mathrm{~mm}$ in length) and dried, the processed mixtures were tested for its thermooxidative stabilization performance. Images depicting the visual aspect of the processed PP loaded with the cork extracts can be found in Fig. 3, for a loading level of $1.5 \%$.

The performance of cork extracts as thermo-oxidative stabilizing agents was assessed by measurement of the OOT and the OIT. The obtained results are presented in Table 4 and the DSC curves for the OOT and the OIT assays are presented in Figs. 4 and 5, respectively. For comparison purposes, a sample of PP containing $0.5 \%$ loading of a commercially available hindered phenolic antioxidant (i.e. Pentaerythritol tetrakis(3-(3,5-di-tert-butyl-4-hydroxyphenyl) propionate) also known commercially as Irganox 1010) was also compounded and analyzed.

The results clearly demonstrate that the E_EtOH presents the highest performance as a stabilizing additive for PP; the E_H2O is the least effective followed by the E_EtOH50.

The E_H2O, in both tests, OOT and OIT, has a performance that compares to the raw PP. That is, the presence of the extract does not contribute to the protection of the polymer, even considering the 1.5\% loading level. The E_EtOH50 shows improved results when compared to the E_H2O, with higher OOT and OIT values. However, this improvement is only marginal when compared to the raw PP and to other extracts. The OOT is $222.1{ }^{\circ} \mathrm{C}$ for $0.5 \%$ and $223.9{ }^{\circ} \mathrm{C}$ for

Table 3

Yield, total phenolic content (TPC), dpph radical scavenging and oxygen radical absorbance capacity of cork extracts.

\begin{tabular}{|c|c|c|c|c|}
\hline Extract & Yield, \%m/m & TPC, mgGA ${ }_{\text {eq }} / g_{\text {extract }}$ & $\mathrm{dpph}, \mathrm{EC}_{50} \mu \mathrm{g} / \mathrm{mL}$ & ORAC, TE \\
\hline E_EtOH & $5.8 \pm 0.4$ & $396 \pm 17$ & $9.44 \pm 0.54$ & $1.88 \pm 0.20$ \\
\hline E_EtOH50 & $9.3 \pm 0.2$ & $570 \pm 39$ & $5.32 \pm 0.45$ & $2.11 \pm 0.24$ \\
\hline E_H2O & $6.7 \pm 1.0$ & $486 \pm 6$ & $6.33 \pm 0.38$ & $1.21 \pm 0.25$ \\
\hline
\end{tabular}



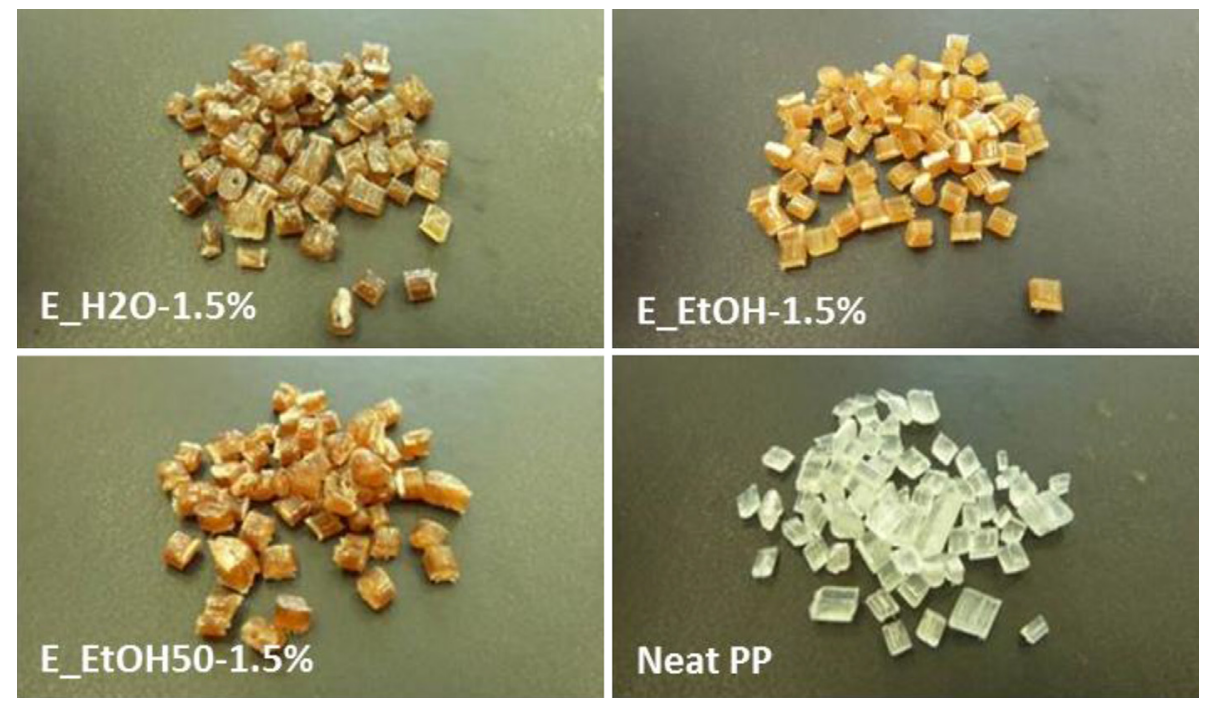

Fig. 3. Images of pellets of neat PP and PP loaded with cork extracts (at 1.5\%).

Table 4

OOT $\left({ }^{\circ} \mathrm{C}\right)$ values and OIT (min) values determined at 200 and $220^{\circ} \mathrm{C}$.

\begin{tabular}{llcl}
\hline Mixture & OOT $/{ }^{\circ} \mathrm{C}$ & OIT @200 ${ }^{\circ} \mathrm{C} / \mathrm{min}$ & OIT @220 ${ }^{\circ} \mathrm{C} / \mathrm{min}$ \\
\hline Neat PP & $216.2 \pm 0.8$ & $3.83 \pm 0.08$ & $1.18 \pm 0.40$ \\
E_H2O-0.5\% & $215.7 \pm 0.1$ & $3.83 \pm 0.13$ & - \\
E_H2O-1.5\% & $216.0 \pm 0.5$ & $3.80 \pm 0.10$ & - \\
E_EtOH-0.5\% & $241.7 \pm 0.7$ & $24.28 \pm 0.17$ & $6.55 \pm 0.11$ \\
E_EtOH-1.5\% & $246.9 \pm 0.7$ & $29.72 \pm 0.51$ & $9.00 \pm 0.01$ \\
E_EtOH50-0.5\% & $222.1 \pm 1.1$ & $6.83 \pm 0.13$ & - \\
E_EtOH50-1.5\% & $223.9 \pm 0.2$ & $7.01 \pm 0.52$ & $1.77 \pm 0.10$ \\
IR-0.5\% & $247.5 \pm 0.5$ & $60.31 \pm 3.10$ & $11.91 \pm 0.31$ \\
\hline
\end{tabular}

$1.5 \%$ which compares to $216.2{ }^{\circ} \mathrm{C}$ for the neat PP. The OIT is $6.83 \mathrm{~min}$ and $7.01 \mathrm{~min}$ for $0.5 \%$ and $1.5 \%$, which represent a small increase over the value determined for the neat PP (3.83 min). Also of notice (from the results for the E_H2O and E_EtOH50) is that, even with an increase of the loading percentage, the OOT and OIT suffer only a marginal improvement.

In contrast, it is observed a significant improvement of the OOT values for the PP loaded with the E_EtOH, when compared with the

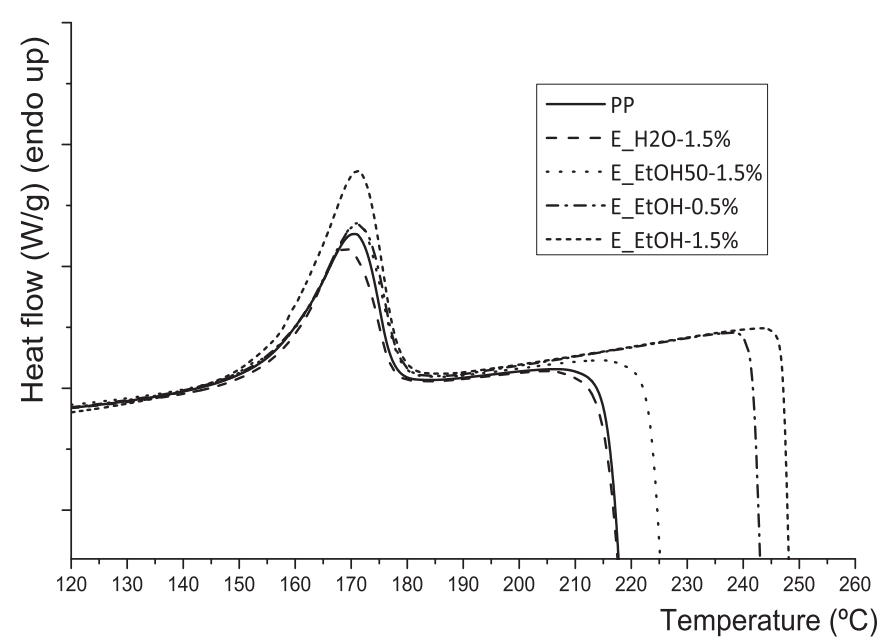

Fig. 4. OOT $\left({ }^{\circ} \mathrm{C}\right)$ determined for neat PP and for the polymer loaded with the E_EtOH50, E_H2O (1.5\%) and E_EtOH (0.5\% and 1.5\%). neat PP. The temperature of oxidation, for $0.5 \%$ and $1.5 \%$ loading levels was $241.7{ }^{\circ} \mathrm{C}$ and $246.9{ }^{\circ} \mathrm{C}$, respectively. These values compare with $216.2^{\circ} \mathrm{C}$ for the neat PP and $247.5^{\circ} \mathrm{C}$ for the PP loaded with the commercial antioxidant. The OIT at $200{ }^{\circ} \mathrm{C}$ was determined to be $24.28 \mathrm{~min}$ for $0.5 \%$ and $29.72 \mathrm{~min}$ for $1.5 \%$, significantly higher than 3.83 min observed for the neat PP. Anyway, it represents, approximately, $40 \%$ and $50 \%$ of the commercial antioxidant performance (sample IR-0.5\% in Table 4). The OIT values for $220{ }^{\circ} \mathrm{C}$ show, as expected, a strong decrease from the ones registered for $200{ }^{\circ} \mathrm{C}$. The OIT, of the PP loaded with E_EtOH, at $220{ }^{\circ} \mathrm{C}$ was measured to be $6.55 \mathrm{~min}$ and $9.00 \mathrm{~min}$ for the $0.5 \%$ and $1.5 \%$ loading, respectively. Indeed, these values represent 55\% and 75\%, of the performance determined for the commercial antioxidant. The increase in the testing temperature to $220{ }^{\circ} \mathrm{C}$ leads to an improvement of the relative performance of the E_EtOH over the commercial antioxidant.

Overall, the results obtained for OOT and OIT show that, for the selected cork extracts, the E_EtOH was the only one who provided effective protection against the thermo-oxidation of PP. This observation is in contrast with what was expected for the

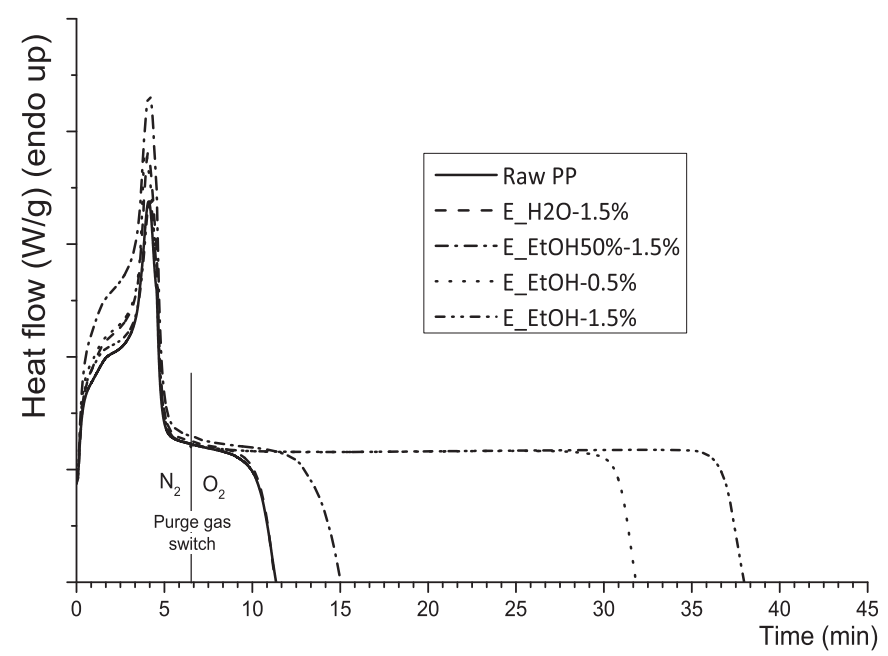

Fig. 5. OIT $\left(200^{\circ} \mathrm{C}\right)$ DSC curves for neat PP and for PP loaded with the E_EtOH50, E_H2O (1.5\%) and E_EtOH (0.5\% and 1.5\%). 


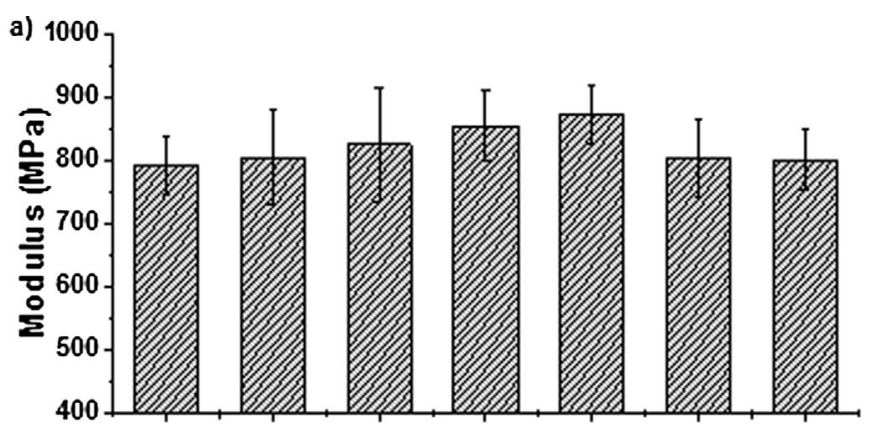

b)
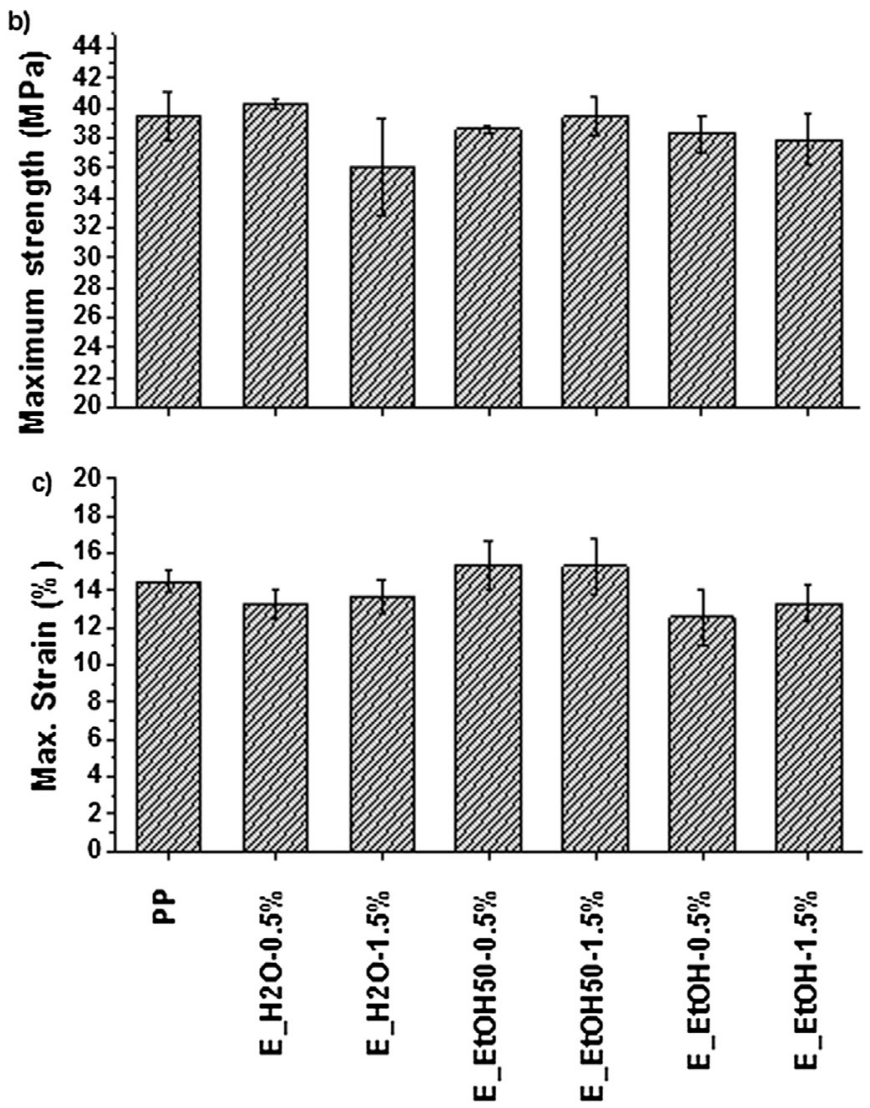

Fig. 6. Tensile properties of PP and PP-Cork extracts: a) tensile modulus, b) maximum tensile strength and c) maximum strain at yield point.

antioxidant properties of the tested extracts, where the E_EtOH50 presents the highest performance both at the radical scavenging and quenching of oxygen reactive species.

A possible explanation for this observation may reside on the type of molecules that are extracted by each solvent. The extracts obtained with water and ethanol:water (50:50) are constituted by molecules of higher polarity than those present on the ethanol extract, reflecting the properties of the extracting medium. PP is non-polar which can result in incompatibility between the polymeric matrix and these extracts. During the oxidative process, the radicals formed within the polymeric material must be rapidly transferred to the antioxidant systems for stabilization and to avoid the propagation of the chain breaking reactions. Therefore, the antioxidant molecules must be deeply embedded within the polymer matrix for an effective function. If a barrier subsists, the antioxidant system performance will be severely compromised. Therefore, despite of the lower antioxidant capacity revealed, the ethanol extract molecules are more effective in the oxidative protection of PP. Further studies will be required to fully elucidate this possibility.

\subsection{Mechanical properties}

The mechanical performance of PP loaded with the different cork extracts was evaluated under tensile load by stress-strain mechanical test. The stress-strain curves show similar behavior independent of the presence of cork extract and irganox as additives, or for neat PP. During the assay, it is observed that the break of the testing sample occurred at the maximum load or shortly after this. Therefore, for clarity and uniformity of results, it is presented the maximum strain at the yield point, for all specimens and for all conditions. The values obtained for tensile modulus, maximum strength and maximum strain at yield point are presented in Fig. 6 .

The tensile modulus, maximum strength and maximum strain, measured for the processed mixtures, are statistically similar to the neat PP. Therefore, and despite the increase of the OOT and OIT, the results for the mechanical properties do not allow concluding about the protective effect of the extracts, during the processing stage (which occurs under poor oxygen atmosphere). Nevertheless, the mechanical evaluation indicates that the presence of the cork extracts does not negatively affect the mechanical performance of the PP matrix. The results presented further confirm the potential of the cork extracts to be explored as stabilizing and anti-oxidant additives to PP in a natural and eco-friendly perspective.

\section{Conclusions}

The presented results show that $\mathrm{PP}$-cork composites have intrinsic protection against thermo-oxidation processes and that this protection is provided by cork, more specifically, by the ethanol soluble fraction present in the cork extractives fraction. After isolation of these components and its direct compounding with PP by twin-screw extrusion, it was demonstrated that the protective effect is retained. Mechanical analysis of the PP loaded with the cork extracts up to 1.5 wt.\% show no compromise on the mechanical properties under tensile load. The feasibility of the cork extractives as bio-based thermal-oxidation stabilizers for PP has been demonstrated, opening new routes of valorization for this natural resource.

\section{Acknowledgments}

The authors are grateful to Amorim Cork Composites for providing the cork powder raw material. Ivo Aroso and Emanuel Fernandes are grateful for financial support of FCT through grants SFRH/BD/42273/2007 and SFRH/BPD/96197/2013, respectively. Funding was also granted from the European Union's Seventh Framework Programme (FP7/2007-2013) under grant agreement $\mathrm{n}^{\circ}$ REGPOT-CT2012-316331-POLARIS and from Project "Novel smart and biomimetic materials for innovative regenerative medicine approaches (Ref.: RL1-ABMR-NORTE-01-0124-FEDER000016)" co-financed by North Portugal Regional Operational Programme (ON.2 - O Novo Norte), under the National Strategic Reference Framework (NSRF), through the European Regional Development Fund (ERDF).

\section{References}

[1] Gil L, Moiteiro C. Cork. Ullmann encyclopedia of industrial chemistry. Weinheim: Wiley-VCH; 2002. p. 503-21.

[2] APCOR. Yearbook 2013.

[3] Pinto PCRO, Sousa AR, Silvestre AJD, Neto CP, Gandini A, Eckerman C, et al. Quercus suber and Betula pendula outer barks as renewable sources of oleochemicals: a comparative study. Ind Crops Prod 2009;29:126-32. 
[4] Silva SP, Sabino MA, Fernandes EM, Correlo VM, Boesel LF, Reis RL. Cork: properties, capabilities and application. Int Mater Rev 2005:50:345-65.

[5] Conde E, Cadahía E, García-Vallejo MC, González-Adrados JR. Chemical characterization of reproduction cork from Spanish Quercus suber. J Wood Chem Technol 1998;18:447-69.

[6] Mano JF. Creep-recovery behaviour of cork. Mater Lett 2007:61:2473-7.

[7] Mano JF. The viscoelastic properties of cork. J Mater Sci 2002;37:257-63.

[8] Mano JF, Correia NT, Ramos JJM, Saramago B. The molecular relaxation mechanisms in cork as studied by thermally stimulated discharge currents. J Mater Sci 1995;30:2035-41.

[9] Gil L. Cork composites: a review. Materials 2009;2:776-89.

[10] Fernandes EM, Correlo VM, Chagas JAM, Mano JF, Reis RL. Cork based composites using polyolefin's as matrix: morphology and mechanical performance. Compos Sci Technol 2010;70:2310-8.

[11] Fernandes EM, Correlo VM, Chagas JAM, Mano JF, Reis RL. Properties of new cork-polymer composites: advantages and drawbacks as compared with commercially available fibreboard materials. Compos Struct 2011;93:3120-9.

[12] Fernandes EM, Correlo VM, Mano JF, Reis RL. Polypropylene-based cork-polymer composites: processing parameters and properties. Compos Part B: Eng 2014;66:210-23.

[13] Fernandes EM, Aroso I, Pires RA, Correlo VM, Pitkänen P, Koskimies S, et al. Improvement on the mechanical properties of cork composites using suberin as coupling agent through a reactive extrusion process. 2011. p. 611-5. Boston, MA.

[14] Fernandes EM, Aroso IM, Covas JA, Mano JF, Reis RL. Functionalized cork-polymer composites (CPC) by reactive extrusion using suberin and lignin from cork as coupling agents. Compos Part B: Eng 2014;67:371-80.

[15] Fernandes EM, Correlo VM, Mano JF, Reis RL. Natural fibres as reinforcement strategy on cork-polymer composites. In: Pinto AMP, Pouzada AS, editors. Advanced materials forum VI, pts 1 and 2; 2013. p. 373-8.

[16] Fernandes EM, Correlo VM, Mano JF, Reis RL. Novel cork-polymer composites reinforced with short natural coconut fibres: effect of fibre loading and coupling agent addition. Compos Sci Technol 2013;78:56-62.

[17] Fernandes EM, Mano JF, Reis RL. Hybrid cork-polymer composites containing sisal fibre: morphology, effect of the fibre treatment on the mechanical properties and tensile failure prediction. Compos Struct 2013;105:153-62.

[18] Ben Abdallah F, Ben Cheikh R, Baklouti M, Denchev Z, Cunha AM. Effect of surface treatment in cork reinforced composites. J Polym Res 2010;17: 519-28.

[19] Ben Abdallah F, Ben Cheikh R, Baklouti M, Denchev Z, Cunha AM. Characterization of composite materials based on PP-cork blends. J Reinf Plast Compos 2006;25:1499-506.

[20] Antunes PJ, Dias GR, Coelho AT, Rebelo F, Pereira T. Hyperelastic modelling of cork-polyurethane gel composites: non-linear FEA implementation in 3D foot model. Mater Sci Forum 2008:700-5.

[21] Oprea S. Effects of fillers on polyurethane resin-based polyurethane elastomeric bearing materials for passive isolation. J Compos Mater 2008;42: $2673-85$.

[22] Fernandes EM, Correlo VM, Mano JF, Reis RL. Innovative bio-based composites comprising cork and biodegradable polyester. In: Ferreira JAM, editor. 16th International conference on composite structures (ICCS16). Porto: FEUP; 2011.
[23] Vilela C, Sousa AF, Freire CSR, Silvestre AJD, Pascoal Neto C. Novel sustainable composites prepared from cork residues and biopolymers. Biomass Bioenergy 2013;55:148-55.

[24] Zaikov GE, Polishchuk AY. New aspects of the problem of polymers aging and stabilization. Usp Khim+1993;62:644-64.

[25] Pospisil J, Nespurek S. Chain-breaking stabilizers in polymers - the current status. Polym Degrad Stabil 1995;49:99-110.

[26] Bhowmick AK, White JR. Thermal, UV- and sunlight ageing of thermoplastic elastomeric natural rubber-polyethylene blends. J Mater Sci 2002;37: 5141-51.

[27] Huntink NM, Datta RN, Noordermeer JWM. Addressing durability of rubber compounds. Rubber Chem Technol 2004;77:476-511.

[28] Girois S, Audouin L, Delprat P, Verdu J. Weight loss mechanism in the photooxidation of polypropylene. Polym Degrad Stabil 1996;51:133-41.

[29] Girois S, Audouin L, Verdu J, Delprat P, Marot G. Molecular weight changes during the photooxidation of isotactic polypropylene. Polym Degrad Stabil 1996;51:125-32.

[30] Almalaika S. Mechanisms of antioxidant action and stabilization technology the Aston experience. Polym Degrad Stabil 1991;34:1-36.

[31] Ambrogi V, Cerruti P, Carfagna C, Malinconico M, Marturano V, Perrotti M et al. Natural antioxidants for polypropylene stabilization. Polym Degrad Stabil 2011;96:2152-8

[32] Morici E, Arrigo R, Dintcheva NT. Quercetin as natural stabilizing agent for bio-polymer. AIP Conf Proc 2014;1599:314-7.

[33] Oliveira RJB, Forrester AMS, Marques MFV. In-reactor stabilization of poly(propylene) with natural antioxidants. Macromol Symp 2011;299-300:215-9.

[34] Ambrogi V, Panzella L, Persico P, Cerruti P, Lonz CA, Carfagna C, et al. An antioxidant bioinspired phenolic polymer for efficient stabilization of polyethylene. Biomacromolecules 2014;15:302-10.

[35] Cordeiro N, Belgacem MN, Silvestre AJD, Neto CP, Gandini A. Cork suberin as a new source of chemicals. 1. Isolation and chemical characterization of its composition. Int J Biol Macromol 1998;22:71-80.

[36] Singleton VL, Rossi JA. Colorimetry of total phenolics with phosphomolybdic-phosphotungstic acid reagents. Am J Enol Vitic 1965:16:144-58.

[37] Santos SAO, Pinto PCRO, Silvestre AJD, Neto CP. Chemical composition and antioxidant activity of phenolic extracts of cork from Quercus suber L. Ind Crops Prod 2010:31:521-6.

[38] Huang D, Ou B, Hampsch-Woodill M, Flanagan JA, Prior RL. High-throughput assay of oxygen radical absorbance capacity (ORAC) using a multichannel liquid handling system coupled with a microplate fluorescence reader in 96well format. J Agric Food Chem 2002:50:4437-44.

[39] Santos SAO, Villaverde JJ, Sousa AF, Coelho JFJ, Neto CP, Silvestre AJD. Phenolic composition and antioxidant activity of industrial cork by-products. Ind Crops Prod 2013:47:262-9.

[40] Conde E, Lopez MDC, Moure A, Vilarino JML, Dominguez H, Lopez MJA, et al. An approach to assess the synergistic effect of natural antioxidants on the performance of the polypropylene stabilizing systems. J Appl Polym Sc 2012;126:1852-8. 